Florida International University

FIU Digital Commons

\title{
The Moderating Mediation Effects of Maternal Psychological Control and Maternal Acceptance on the Relation Between Maternal Acculturation and Youth Anxiety
}

Ileana Hernandez

Florida International University, ihern003@fiu.edu

DOI: $10.25148 /$ etd.FI12050210

Follow this and additional works at: https://digitalcommons.fiu.edu/etd

\section{Recommended Citation}

Hernandez, Ileana, "The Moderating Mediation Effects of Maternal Psychological Control and Maternal Acceptance on the Relation Between Maternal Acculturation and Youth Anxiety" (2012). FIU Electronic Theses and Dissertations. 599.

https://digitalcommons.fiu.edu/etd/599 


\title{
FLORIDA INTERNATIONAL UNIVERSITY \\ Miami, Florida
}

THE MODERATING MEDIATION EFFECTS OF MATERNAL PSYCHOLOGICAL CONTROL AND MATERNAL ACCEPTANCE ON THE RELATION BETWEEN MATERNAL ACCULTURATION AND YOUTH ANXIETY

\author{
A thesis submitted in partial fulfillment of the \\ requirements for the degree of \\ MASTER OF SCIENCE \\ in \\ PSYCHOLOGY \\ by \\ Ileana Hernandez
}

2012 
To: Dean Kenneth G. Furton

College of Arts and Sciences

This thesis, written by Ileana Hernandez, and entitled The Moderating Mediation Effects of Maternal Psychological Control and Maternal Acceptance on the Relation between Maternal Acculturation and Youth Anxiety, having been approved in respect to style and intellectual content, is referred to you for judgment.

We have read this thesis and recommend that it be approved.

William M. Kurtines

Jeremy Pettit

Wendy K. Silverman, Major Professor

Date of Defense: January 30, 2012

The thesis of Ileana Hernandez is approved.

$\begin{array}{r}\begin{array}{r}\text { Dean Kenneth G. Furton } \\ \text { College of Arts and Sciences }\end{array} \\ \hline \begin{array}{r}\text { Dean Lakshmi N. Reddi } \\ \text { University Graduate School }\end{array}\end{array}$

Florida International University, 2012 


\begin{abstract}
OF THE THESIS
THE MODERATING MEDIATION EFFECTS OF MATERNAL PSYCHOLOGICAL CONTROL AND MATERNAL ACCEPTANCE ON THE RELATION BETWEEN MATERNAL ACCULTURATION AND YOUTH ANXIETY
\end{abstract} by

Ileana Hernandez

Florida International University, 2012

Miami, Florida

Professor Wendy K. Silverman, Major Professor

The present study examined the relations among maternal psychological control, maternal acceptance, maternal acculturation and youth anxiety within the framework of a (partially) moderated mediation model. The sample consisted of 535 Hispanic-Latino youth ( $46 \%$ girls; $M=9.79$ years) and their mothers. The study's data were analyzed using structural equation modeling in the MPlus statistical software program.

Results indicated that maternal psychological control and youth anxiety are significantly and positively related. Results also indicated that more acculturated mothers were more psychologically controlling than less acculturated mothers. Results further provided evidence for a partial mediational role of maternal psychological control on the relation between maternal acculturation and youth anxiety symptoms. In addition, there was a direct, positive relation between maternal acculturation and youth anxiety symptoms. No significant findings were observed regarding the moderating role of maternal acceptance on the relation between maternal psychological control and youth anxiety. The findings' theoretical and clinical implications are further discussed. 


\section{TABLE OF CONTENTS}

CHAPTER

PAGE

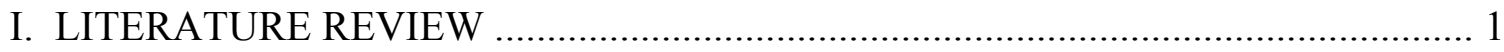

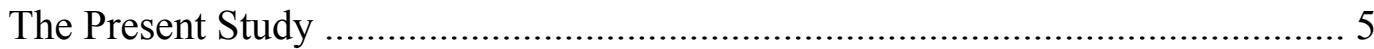

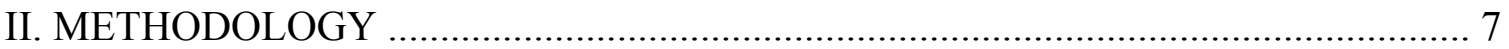

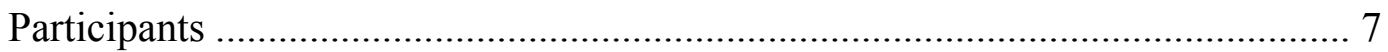

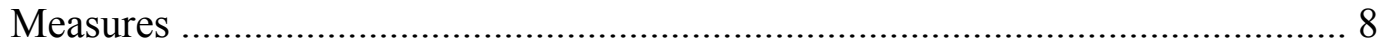

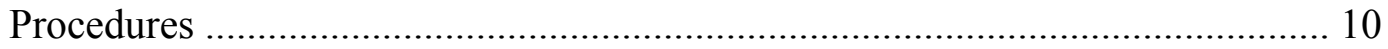

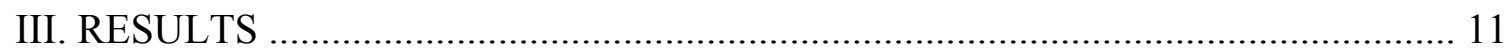

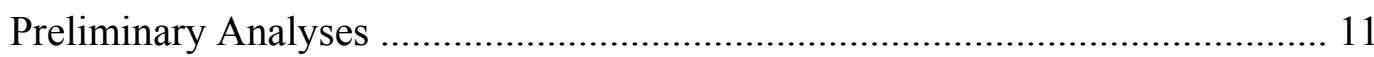

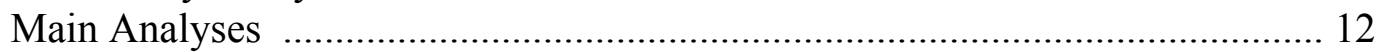

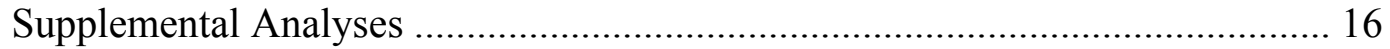

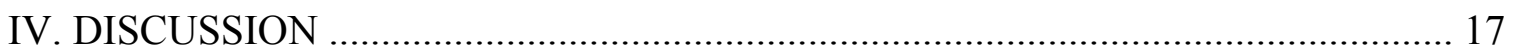

Limitations and Future Research Directions ...................................................... 20

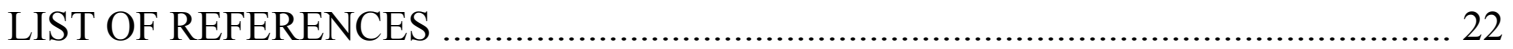

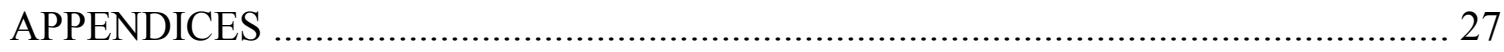




\section{LIST OF FIGURES}

FIGURE

PAGE

1. Conceptual Moderated Mediation Model ............................................................. 30

2. Youth Moderated Mediation Model .......................................................................... 31

3. Youth Mediation Model ....................................................................................... 32

4. Parent Moderated Mediation Model .......................................................................... 33

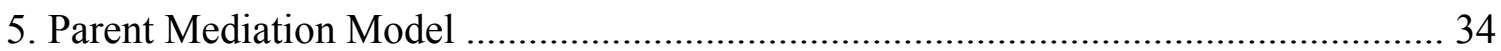




\section{CHAPTER I.}

\section{LITERATURE REVIEW}

Theoretical models on the development and maintenance of anxiety and its disorders in youth have emphasized the role of parenting (e.g., Chorpita \& Barlow, 1998; Chorpita, Brown, \& Barlow, 1998; Ginsburg, Siqueland, Masia-Warner, \& Hedtke, 2004; Rapee, 2001). These models propose that excessive parental control can result in the development of anxiety (Chorpita et al., 1998; Vasey \& Dadds, 2001). Specifically, conceptual models have hypothesized that parents who exert excessive control and do not grant autonomy in developmentally salient tasks are more likely to foster a diminished sense of control in their child and thus lead to high levels of child anxiety (Wood, 2006). Other models (e.g., Chorpita et al., 1998; Wood, McLeod, Sigman, Hwang, \& Chu, 2003) have hypothesized that parents who encourage children's autonomy and independence, such as in unfamiliar situations, may increase their child's perception of mastery over the environment and thus lead to child anxiety reduction.

The research literature investigating the role of parental control on youth internalizing problems is complicated, however, because it contains many different conceptualizations of control (e.g., Barber, 1992; Rollins \& Thomas, 1979; Weems \& Silverman, 2006). A valuable contribution to the understanding of parental control and its role on youth anxiety has been the differentiation between parental behavioral and psychological control (e.g., Barber, 1996; Schaefer, 1965; Steinberg, 1990). Behavioral control refers to parental behaviors that attempt to control or manage the youth's actions (e.g., limit setting, inflicting consequences) (Barber, 1996). Psychological control refers 
to parental behaviors that attempt to inhibit or intrusively control the psychological and emotional development of the youth (e.g., guilt induction, shame) (Barber, 1996).

According to Steinberg (1990), psychological control, or the absence of granting youth psychological autonomy, adversely affects youth well-being; behavioral control, or the presence of parent demandingness, positively influences youth well-being. Further, parental behavioral and psychological control are differentially related to internalizing and externalizing problems. The research literature shows psychological control is consistently predictive of youth internalizing problems, whereas behavioral control is predictive of externalizing problems (e.g., Barber, 1996; Becker, 1964; McLeod, Wood, $\&$ Weisz, 2007). As such, the present study focuses on parental psychological control.

Theorists have further suggested parental acceptance serves as a buffer between parental control and youth anxiety. Parental acceptance refers to parental warmth and support (e.g., Clark \& Ladd, 2000; Maccoby, 1992). Theories suggest that parental acceptance is related to the development of the child's view of the world as consistent and safe, which may protect against the development of anxiety (e.g., Andersson \& Perris, 2000). Thus, in the presence of high parental control, parental acceptance may act as a moderator variable. Studies examining the interaction of parental control and parental acceptance on youth anxiety have been scarce. The few studies that have examined this interaction employed a broad conceptualization of parental control and have produced inconsistent findings (e.g., Rapee, 1997; Wood et al., 2003). The present study therefore examined parental acceptance as a moderator of the relation between parental psychological control and youth anxiety. 
Although most of the research examining the role of parental control and anxiety in youth has been conducted using predominantly European-American samples, there is some research suggesting that this relation is also true for Hispanic-Latino parents and their children. The scant research that has been conducted suggests Hispanic-Latino parents employ more psychological control over their children's behaviors than their European-American counterparts (e.g., Durrett, O’Bryant, \& Pennebaker, 1975; Julian, McKenry, \& McKelvey, 1994). However, whether Hispanic-Latino parents' psychological control is also associated with their children's anxiety is unknown. Examining this link among Hispanic-Latinos is important given this group has high prevalence rates of anxiety disorders (Novy, Stanley, Averill, \& Daza, 2001). In addition, the Hispanic-Latino population has become the largest minority group in the United States (U.S. Census Bureau, 2006) and is expected to continue to grow because of the influx of new immigrants (U. S. Census Bureau, 2010).

The influx of new Hispanic-Latino immigrants brings to the forefront the importance of including an examination of the role of parental acculturation. Acculturation involves individuals' changes that result from continuous contact between two or more distinct cultures (Berry, 1980). Although immigrants may retain aspects of their ethnic culture when they adapt to mainstream culture, the majority of immigrants incorporate gradually the values and norms of the host society (Rogler, Cortes, \& Malgady, 1991).

There is some research suggesting that more acculturated mothers of HispanicLatino descent are less psychologically controlling in their parental approaches than less acculturated mothers (Knight, Virdin, \& Roosa, 1994). One explanation for this is that 
parenting beliefs and practices reflect family values and shifts in childrearing attitudes and values may occur as parents become acculturated to the mainstream culture (Okagaki \& Sternberg, 1993). The mainstream U.S. culture, for example, emphasizes the values of independence and autonomy granting more than Hispanic-Latino culture, which stresses the importance of interdependence (e.g., Bulcroft, Carmody, Bulcroft, 1996; Driscoll, Russell, \& Crockett, 2008; Roosa, Morgan-Lopez, Cree, \& Spector, 2002). The present study therefore posited that more acculturated Hispanic-Latino parents may exercise less psychological control of their child than less acculturated parents. This, in turn, may foster a sense of independence and autonomy in the child and therefore reduced anxiety. That is, parental psychological control may potentially mediate the relationship between parental acculturation and youth anxiety.

Although research on immigrant families has shown parental acculturation is related to emotional well-being of Hispanic-Latino youth, no study has examined whether a link exists between mother's level of acculturation and youth anxiety. Two studies found evidence for a relation between mother's level of acculturation and youth depressive symptoms in community samples of Mexican-American mothers and their children (Dumka, Roosa, \& Jackson, 1997; Knight et al., 1994), but the findings across the two studies were inconsistent. Knight et al. (1994) found high maternal acculturation levels predicted increased youth depressive symptoms; Dumka et al. (1997) found high maternal acculturation predicted decreased youth depressive symptoms. Gonzales, Knight, Morgan-Lopez, Saenz, and Sirolli (2002) noted that these inconsistent findings may be due to differences in the mothers' acculturation levels represented in the sample, as measured by the Acculturation Rating Scale for Mexican Americans (ARMSA; 
Cuellar, Harris, \& Jasso, 1980). Dumka et al.'s (1997) sample was predominately immigrant and unacculturated Mexican-American mothers; Knight et al.'s (1994) was limited to predominately more acculturated mothers. Although these studies looked at youth internalizing problems (i.e., depressive symptoms), no study has examined whether a relation also exists between mother's level of acculturation and youth anxiety.

\section{The Present Study}

Taken together, research suggests parental psychological control may play a partial mediational role in the relation between parental acculturation and anxiety among Hispanic-Latino youth. Further, parental acceptance may serve as a moderator of the relation between parental psychological control and youth anxiety. Therefore, the purpose of this study was to examine the relations among maternal psychological control, maternal acceptance, maternal acculturation and youth anxiety within the framework of a (partially) moderated mediation model in a sample of Hispanic-Latino youth referred to an anxiety disorders specialty research clinic. The study's conceptual model is depicted in Figure 1.

It was hypothesized that mothers and youth who report high levels of maternal psychological control will also report high levels of youth anxiety. Additionally, it was hypothesized that less acculturated mothers and their youth will report high levels of maternal psychological control. Because of the absence of past research, it was viewed premature to formulate specific hypotheses with respect to 1) the relation between mother's level of acculturation and youth anxiety, 2) maternal acceptance as a moderator variable, and 3) the mediational role of maternal psychological control. Also of interest 
was to explore whether youth sex moderates the mediated relations tested in the conceptual model. 


\section{CHAPTER II.}

\section{METHODOLOGY}

\section{Participants}

Participants were 535 Hispanic-Latino youth (ages 6 to 16 years, $M=9.79 ; S D=$ 2.50) and their mothers who presented to the Child Anxiety and Phobia Program (CAPP) at Florida International University, an anxiety disorders specialty research clinic, for difficulties with fears and/or anxiety. The sample contained 244 girls and 291 boys. In terms of mothers' nationalities, 158 (29.5\%) were born in Cuba, 122 (22.8\%) were born in the United States, $46(8.6 \%)$ were born in Colombia, $40(7.5 \%)$ were born in Nicaragua, 135 (25.3\%) were born in other Latin American countries, and 34 (6.3\%) did not report nationality. Although $3.6 \%$ of the youth did not complete the semi-structured diagnostic interview, these data were included in the present study because these youth participants completed the study's questionnaires. Of the 523 youth for which diagnosis were obtained, $88 \%$ of youth met Diagnostic and Statistical Manual of Mental Disorders (DSM-IV; American Psychiatric Association, 1994) criteria for the presence of an anxiety disorder in their diagnostic profile. The most common primary diagnoses were separation anxiety disorder $(29.0 \%)$, social phobia $(21.1 \%)$, generalized anxiety disorder (17.2\%), and specific phobia (10.1\%), with the remainder (15.1\%) being anxiety and other diagnoses. A more detailed description of sociodemographic characteristics and primary diagnoses are listed in Table 1 and 2, respectively. 
Primary referral sources are typically school counselors, mental health professional and pediatricians. Participants were included if their mother reported them to have difficulties related to anxiety symptoms during an initial telephone screen. Exclusionary criteria for participation in this study were developmental delays (e.g., Asperger's syndrome, mental retardation, autism) or severe psychopathology (e.g., schizophrenia).

\section{Measures}

Demographics. Mothers completed an information form that inquired the demographics of the mother and youth, including the youth's age and gender, child and mother's ethnicity, and family socioeconomic status.

Parenting Behavior Inventory (Child Report/Parent Report; CRPBI/PRPBI; Schludermann \& Schludermann, 1970). The CRPBI/PRPBI assess respondents' perceptions of the parent's behaviors toward the youth. The present study employed the 30-item version, which is composed of three subscales- Psychological Control (CRPBI/PRPBI-PC), Acceptance (CRPBI/PRPBI-MA), and Firm Control, each consisting of 10 items. The Psychological Control and Acceptance subscale scores were analyzed in this study. For each item, the child and mother respond to items on a 3-point Likert scale, indicating whether that statement is "Not like", "Somewhat like", or "A lot like" the mother's behavior toward the youth. The internal consistency of the subscales has been found to range from .65 to .74 (Schwartz, Barton-Henry, \& Pruzinsky, 1985). The PRPBI and CRPBI have been used in samples of youth referred to youth anxiety clinics and have been found to have satisfactory psychometrics (Siqueland, Kendall, \& 
Steinberg, 1996). The alpha coefficients for the CRPBI and PRPBI in the current study were .79 and .72 , respectively.

Revised Children's Manifest Anxiety Scale (RCMAS; Reynolds \& Richmond, 1978). The RCMAS consists of 37 items that assess youths' anxiety symptoms. Twentyeight items are summed to provide a Total Anxiety score. Respondent rate each item as either Yes or No and scored 1 or 0 , respectively. The measure yields three anxiety factors: Physiological Symptoms, Worry/Oversensitivity, and Concentration Problems. Total Anxiety scores range from 0 to 28 , with higher scores indicating higher levels of anxiety. Pela and Reynolds (1982) reported a 3-week test-retest reliability of .98 for the Total Anxiety scale. The alpha coefficient for the RCMAS in this sample was .84 .

Revised Children's Manifest Anxiety Scale, Parent Version (RCMAS-P; Reynolds \& Richmond, 1978). In the RCMAS-P, the wording was changed from "I..." to "My child..." as done in past research (e.g., Kendall, 1994; Silverman et al., 1999). Respondents rate each item as either Yes or No and scored 1 or 0 , respectively. Twenty-eight items are summed to provide a Total Anxiety score. As in the original version of the scale, RCMAS-P contains three anxiety subscales: Physiological Anxiety, Worry/Oversensitivity, and Social Concerns/Concentration. The alpha coefficient for the RCMAS-P in this sample was .78.

Stephenson Multigroup Acculturation Scale (SMAS; Stephenson, 2000). The SMAS consists of 32 items that assess behavioral and attitudinal aspects of acculturation that can be applied across ethnic groups and were administered to the mothers in the current study. The SMAS is scored according to two subscales: Ethnic Society Immersion (ESI) and Dominant Society Immersion (DSI). The ESI scale score assesses 
the level to which an individual maintains the values and practices of an ethnic group other than the dominant society and includes items such as, "I speak my native language at home." The DSI scale score assesses the level to which an individual adopts the values and practices of the dominant society and includes items such as, "I think in English." Responses to each item are based on a 4-point Likert response format including: $1=$ True, $2=$ Partly true, $3=$ Partly false, and $4=$ False. Scores are determined by calculating mean item responses and range from 1 to 4. Higher scores on ESI reflect lower acculturation while higher scores on DSI reflect higher acculturation. The alpha coefficients for the ESI and DSI subscales in this sample were .83 and .87 , respectively.

\section{Procedures}

All parents and youths who presented to the clinic first provided informed consent/assent. Subsequently, they were administered a semi-structured diagnostic interview and a battery of questionnaires, including the CRPBI/PRPBI, RCMAS, RCMAS-P and SMAS. The questionnaires were administered by trained graduate or advanced undergraduate research assistants. Prior to completion of each questionnaire, directions for each were read aloud. Individual questionnaire items were read aloud to younger children, as well as youth with reading difficulties, with the youth reading along with the research assistant (who was instructed not to view the youth's responses to reduce the possibility of demand). 


\section{CHAPTER III.}

\section{RESULTS}

\section{Preliminary Analyses}

Outlier analyses were undertaken prior to all major analyses. The analyses were both non-model based and model based. For the former, multivariate outliers were identified by examining leverage indices for each individual and defining an outlier as a leverage score four times greater than the mean leverage. An outlier was found and checked for coding errors. The analysis was then conducted for both with and without the outlier. The results are comparable across the two forms of analysis. An additional set of outlier analyses were pursued using model-based outlier analysis. This involved randomly selecting an indicator for each variable and then regressing the indicator for each endogenous variable onto an indicator for variables that the endogenous variable is assumed to be a linear function of. This analysis uses ordinary least squares (OLS) regression in a limited information estimation framework. Standardized dfbetas were examined for each individual and each predictor as well as the intercept. An outlier is defined as anyone with an absolute standardized dfbeta larger than 1.0. There were no outliers found in the data using this approach. Univariate indices of skewness and kurtosis were examined to determine if the absolute value of any of these indices was greater than 2.0. Non-normality was evident in two of the variables. Results revealed a skewness score of -2.24 and kurtosis score of 7.21 for the PRPBI-MA subscale. Results revealed a kurtosis score of 2.45 for the ESI subscale. To account for the non-normality present in the data, structural equation modeling (SEM) analyses were pursued in MPlus 
(Muthén \& Muthén, 2007) by using an estimator (MLR) robust to violations of normality based on the Huber-White algorithm.

The first step in the analysis of missing data was to determine if there was systematic bias in the patterning of missing data. For a given measure, a dummy variable was constructed to indicate the presence or absence of missing data on that measure. Associations between these dummy variables and demographic as well as other study variables were examined. No significant associations were observed. Given this and coupled with minimal univariate missing data (no more than 10 percent on a given variable), missing data were accommodated in SEM by employing full information maximum likelihood (FIML) missing data methodology (Wothke, 2000).

\section{Main Analyses}

To explore moderator effects and test the meditational models, the data were analyzed using SEM on Mplus Version 6. Figures 2 and 4 represent the youth and parent models, respectively, that were tested.

Interaction effects in the SEM analyses were modeled using product terms, as discussed in Jaccard, Turrisi and Wan (1990) and Jaccard and Wan (1996). The paths reflect differential effects of maternal acceptance between the mediators and the outcome. Given the addition of these product terms in the respective youth and parent models, all continuous variables were mean centered for ease of interpretation of path coefficients (Jaccard \& Turrisi, 2003).

Following recommendations of Bollen and Long (1993), a variety of global fit indices were used, including indices of absolute fit, indices of relative fit and indices of fit with a penalty function for lack of parsimony. These include the traditional overall 
chi-square test of model fit (which should be statistically non-significant), the Root Mean Square Error of Approximation (RMSEA; which should be less than 0.08 to declare satisfactory fit), the Comparative Fit Index (CFI; which should be greater than 0.95); and the standardized root mean square residual (SRMR; which should be less than 0.05).

Mediation Effects. Youth Ratings. Figure 2 represents the model that was tested with youth completed measures. The model yielded an excellent fit to the data. The overall chi square test of model fit was not statistically significant $(\chi 2(1)=.05, p>.05)$. The CFI was 1.00. The RMSEA was 0.00. The $\mathrm{p}$ value for the test of close fit was 0.91 . The SRMR was 0.00 . More focused tests of fit revealed no theoretically meaningful or sizeable modification indices.

With respect to the mediation effects using youth ratings, the joint significance test was used to examine these effects as recommended by MacKinnon et al. (2002). The paths of interest in Figure 2 are $a, b, c, d, e$, and $f$. Paths $a$ and $b$ represent the effects of ESI and DSI, respectively, on CRPBI-PC. Path $c$ represents the effect of CRPBI-PC on RCMAS. Paths $d$ and $e$ represent the effects of ESI and DSI, respectively, on RCMAS. In accordance with the recommendations of MacKinnon et al. (2002), paths $a$ and $c$ need to be statistically significant to conclude CRPBI-PC mediates, to some extent, the relation between ESI and RCMAS. Paths $b$ and $c$ need to be statistically significant to conclude CRPBI-PC mediates, to some extent, the relation between DSI and RCMAS. Finally, path $f$ represents the differential effect of CRPBI-MA between CRPBI-PC and RCMAS. Path $f$ was not statistically significant. Thus, this path was dropped from the model.

The model was re-analyzed without the product term. The model (see Figure 3) was just-identified and thus no fit indices are reported. The standardized residuals 
indicate the proportion of unexplained variance in the endogenous variables. The variables in the model were able to account for $8 \%$ of the variance in the CRPBI-PC scores and $8 \%$ of the variance in the RCMAS scores.

As Figure 3 shows, DSI was a significant predictor of CRPBI-PC. High levels of DSI predicted low levels of CRPBI-PC $(B=-.82, S E=.39, p<.05,95 \% \mathrm{CI}=-1.59$ to 0.05). CRPBI-PC was also a significant predictor of RCMAS scores, holding age constant. High levels of CRPBI-PC predicted high levels of RCMAS scores $(B=.43, S E$ $=.07, p<.001,95 \% \mathrm{CI}=.28$ to .57$)$. Dominant Society Immersion was also a significant predictor of RCMAS scores. High levels of DSI predicted high RCMAS scores $(B=1.18$, $S E=.54, p<.05,95 \% \mathrm{CI}=.11$ to 2.25$)$. All together, these findings demonstrate CRPBIPC mediates the relation between DSI and RCMAS scores. Given these findings, .83 was the total effects of DSI on RCMAS.

Parent Ratings. Figure 4 represents the model that was tested with parent completed measures. The model yielded an excellent fit to the data. The overall chisquare test of model fit was not statistically significant $(\chi 2(1)=.01, p>.05)$. The CFI was 1.00 . The RMSEA was 0.00 . The $\mathrm{p}$ value for the test of close fit was 0.96 . The SRMR was 0.00 . More focused tests of fit revealed no theoretically meaningful or sizeable modification indices.

With respect to treatment mediation effects using parent ratings, again, the joint significance test was used to examine these effects as recommended by MacKinnon et al. (2002). The paths of interest in Figure 4 are $a, b, c, d, e$, and $f$. Paths $a$ and $b$ represent the effects of ESI and DSI, respectively on PRPBI-PC. Path $c$ represents the effect of PRPBIPC on RCMAS-P. Paths $d$ and $e$ represent the effects of ESI and DSI, respectively on 
RCMAS-P. In accordance with the recommendations of MacKinnon et al, paths $a$ and $c$ need to be statistically significant to conclude PRPBI-PC mediates, to some extent, the relation between ESI and RCMAS-P. Paths $b$ and $c$ need to be statistically significant to conclude PRPBI-PC mediates, to some extent, the relation between DSI and RCMAS-P. Finally, path $f$ represents the differential effect of PRPBI-MA between PRPBI-PC and RCMAS-P. Path $f$ was not statistically significant. Thus, this path was dropped from the model.

The model was re-analyzed without the product term. The model (see Figure 5) was just-identified and thus no fit indices are reported. The standardized residuals indicate the proportion of unexplained variance in the endogenous variables. The variables in the model were able to account for $3 \%$ of the variance in the PRPBI-PC scores, and $2 \%$ of the variance in the RCMAS-P scores.

As Figure 5 shows, DSI was a significant predictor of PRPBI-PC. High levels of DSI predicted low levels of PRPBI-PC $(B=-1.15, S E=.42, p<.01,95 \% \mathrm{CI}=-.02$ to .16). Given that only path $b$ was significant, there is not sufficient evidence to conclude that PRPBI-PC mediates the relation between DSI and RCMAS-P scores as reported by parents.

Moderator Analysis of Youth Sex. The moderating role of youth sex on the mediated relation between CRPBI/PRPBI-PC and RCMAS and RCMAS-P scores was only explored with youth rated measures because there was insufficient evidence to support the mediating role of PRPBI-PC with the parent rated measures. Multiple groups solution was pursued in MPlus to test the moderating role of youth sex. The model shown in Figure 2, which had no paths constrained, was just-identified and yielded a chi-square 
of 0 . As such, for the chi-square difference tests, an alternative baseline model was estimated in which the path between the covariate of youth age and youth rated RCMAS scores was constrained to be equal across groups. This model showed a satisfactory fit, $\left(\chi^{2}(1)=4.04, p=.04\right.$, with a scaling correction factor of $1.06(\mathrm{CFI}=0.95, \mathrm{RMSEA}=$ $0.10, \operatorname{SRMR}=0.03)$

To examine functional equivalence, this alternative baseline model was compared with a model in which all paths were constrained to be equal in both groups (referred to as the path equivalence model). The constrained paths were as follows: the path coefficients from youth age to CRPBI-PC; the path coefficients from youth age to RCMAS; the path coefficients from CRPBI-PC to RCMAS; the path coefficients from ESI to RCMAS; the path coefficients from DSI to RCMAS; the path coefficients from ESI on CRPBI-PC; and the path coefficients from DSI to CRPBI-PC (see Figure 2). The chi-square difference test, calculated for the Satorra-Bentler adjusted chi-square (Satorra, 2000), was not significant $(\chi 2 \operatorname{diff}(6)=5.44, p>.05)$, supporting functional equivalence for boys and girls.

\section{Supplemental Analyses}

Supplemental analyses were conducted to explore potential problems of model misspecification. Traditional regression methods in conjunction with product terms were used to test for possible interaction effects between predictors of the endogenous variable in Figures 2 and 4 (Jaccard et al., 1996). The regression equations were dictated by the limited information estimation approach to SEM described by Bollen (1996) and did not suggest the presence of any meaningful interaction effects. 


\section{CHAPTER IV.}

\section{DISCUSSION}

The present study examined the relations among maternal psychological control, maternal acceptance, maternal acculturation and youth anxiety within the framework of a (partially) moderated mediated model in a sample of Hispanic-Latino youth referred to an anxiety disorders specialty research clinic. Specifically, the study examined whether maternal psychological control plays a partial mediational role in the relation between maternal acculturation and anxiety among Hispanic-Latino youth. The study also examined whether maternal acceptance serves as a moderator of the relation between maternal psychological control and youth anxiety.

Consistent with the literature that has accumulated on parental psychological control (e.g. Barber, 1996; Becker, 1964; McLeod et al., 2007) and the study’s hypothesis, the findings demonstrate a significant role for maternal psychological control in the prediction of anxiety symptoms in youth. The findings showed that maternal psychological control and youth anxiety are significantly and positively related based on youth ratings. Although past research has examined this relation, this is the first study to examine the relation of maternal psychological control and youth anxiety in a sample of Hispanic-Latino mothers and their youth referred for anxiety disorders.

There is some research suggesting a relation between maternal acculturation and maternal psychological control in Mexican-American mothers and their children (Knight et al., 1994). The present study was interested in examining this relation in a more diverse Hispanic-Latino sample. Consistent with Knight et al. (1994), the present study also demonstrated a significant role for maternal levels of acculturation in the prediction of 
maternal psychological control, based on both youth and parent ratings. More acculturated Hispanic-Latino mothers were less psychologically controlling than less acculturated Hispanic-Latino mothers. These findings suggest parenting beliefs and practices regarding independence and autonomy granting may shift as Hispanic-Latino parents become more acculturated to the mainstream culture (e.g., Bulcroft et al., 1996; Driscoll et al., 2008; Okagaki et al., 1993; Roosa et al., 2002).

In addition, this is the first study to provide evidence for a partial meditational role of maternal psychological control on the relation between maternal acculturation and youth anxiety symptoms in a sample of Hispanic-Latinos, based on youth ratings. That is, the more immersed the mother is in the dominant culture (i.e., more acculturated), the less maternal psychological control is reported by the child. Additionally, the lower the maternal psychological control, the lower the levels of anxiety symptoms reported by the child. Interestingly, mediation was not found based on parent measures. An explanation for the lack of mediation according to parent ratings could be that parents tend to rate themselves low on psychological control. It may thus be beneficial for future studies to include behavioral observations of psychological control in addition to self-ratings.

The present study was also the first to examine the direct relation between maternal levels of acculturation and youth anxiety symptoms in a sample of HispanicLatinos. Although specific hypothesis were not formulated, the study's findings were surprising. Findings showed a direct, positive relation between maternal acculturation and youth anxiety symptoms based on youth ratings. High levels of maternal acculturation predicted high levels of youth anxiety symptoms. There is some research indicating traditional Hispanic-Latino values (e.g., loyalty, cohesion) may protect youth against 
harmful influences from mainstream society (Denner, Kirby, Coyle, \& Brindis, 2001;

Fuligni, Tseng, \& Lam, 1999). Perhaps this protection erodes as mothers become more acculturated and incorporate attitudes and values of the mainstream culture. Future studies should examine other variables that may be mediating the relation between maternal acculturation and youth anxiety symptoms.

The present study explored whether maternal acceptance moderates the relation between maternal psychological control and youth anxiety. The study examined if in the presence of high psychological control, maternal acceptance served as a buffer, and in turn predicted lower levels of youth anxiety. Sufficient evidence was not provided to conclude that maternal acceptance moderates the relation between maternal psychological control and youth anxiety. Research examining the interaction of parental control and parental acceptance on youth anxiety has been scarce. The studies that have been conducted have used predominantly European-American samples, have employed a broad conceptualization of parental control, and have led to inconsistent findings (e.g., Rapee, 1997; Wood et al., 2003). It will be important to determine whether the present study's findings replicate in future studies also examining the interaction of maternal acceptance and, specifically, maternal psychological control on youth anxiety in a sample of Hispanic-Latinos.

The findings highlight the importance of examining mothers' levels of psychological control and acculturation when working with anxious Hispanic-Latino youth. The findings may hold potentially interesting clinical implications in terms of working with Hispanic-Latino mothers whose youth have high levels of anxiety. The 
findings further suggest that it might be important for clinicians to gather information about mothers' cultural practices and beliefs in the context of youth anxiety treatment.

\section{Limitations and Future Research Directions}

The present study has several limitations that merit consideration when interpreting the results. One limitation is that, although various Hispanic-Latino countries were represented, a significant percentage of the sample consisted of Cuban mothers. Hispanic-Latinos as a whole are a very diverse group, with various Latin American countries having unique cultural experiences that consequently affect the family system differently (Zayas, 1987). It would be valuable for future research to extend this study by allowing comparisons across several Hispanic nationalities.

A second limitation is that the parent participants were mothers. Parental levels of acculturation were evaluated only in the mother, while parenting behaviors (i.e., psychological control and acceptance) were evaluated from participant mother's point of view. However, information from both parents is necessary to obtain a more complete picture of how parental acculturation levels may affect parenting behaviors and in turn affect youth anxiety symptoms. Future research would benefit to include both HispanicLatino mothers and fathers' ratings in the assessment of parental acculturation levels, parenting behaviors, and youth anxiety symptoms.

Another limitation is that the study did not have a measure to assess youth acculturation levels. Assessing youth acculturation levels is particularly important in order to examine acculturation gaps between parents and their youth. Szapocznik and Kurtines (1993) proposed that parent-youth acculturation conflict may lead to youth emotional problems. As such, it will be important for future research to examine the 
influence of parent-youth acculturation gaps within the context of the study's conceptual model. 


\section{LIST OF REFERENCES}

American Psychiatric Association. (1994). Diagnostic and Statistical Manual of Mental Disorders (4 ed.). Washington, DC: Author.

Andersson, P., \& Perris, C. (2000). Perceptions of parental rearing and dysfunctional attitudes: The link between early experiences and individual vulnerability? Nordic Journal of Psychiatry, 54, 405-409.

Barber, B. K. (1992). Family, personality, and adolescent problem behaviors. Journal of Marriage and the Family, 54, 69-79.

Barber, B. K. (1996). Parental psychological control: Revisiting a neglected construct. Child Development, 67, 3296-3319.

Becker, W. C. (1964). Consequences of different kinds of parental discipline. In M. L. Hoffman \& W. W. Hoffman (Eds.), Review of child development research (Vol. 1, pp. 169-208). New York: Russell Sage Foundation.

Berry, J. W. (1980). Acculturation as varieties of adaptation. In A. M. Padilla (Ed.), Acculturation: Theory, models and some new findings (pp. 9-23). Boulder, CO: Westview.

Bollen, K. A. (1996). An alternative two stage least squares (2SLS) estimator for latent variable equations. Psychometrika, 61, 109-121.

Bollen, K.A. and J.S. Long (eds). 1993. Testing Structural Equation Models. Newbury Park, CA: Sage.

Bulcroft, R. A., Carmody, D. C., \& Bulcroft, K. A. (1996). Patterns of parental independence giving to adolescents: Variations by race, age, and gender of child. Journal of Marriage \& the Family, 58, 866-883.

Chorpita, B. F., \& Barlow, D. H. (1998). The development of anxiety: The role of control in the early environment. Psychological Bulletin, 124, 3-21.

Chorpita, B. F., Brown, T. A., \& Barlow, D. H. (1998). Perceived control as a mediator of family environment in etiological models of childhood anxiety. Behavior Therapy, 29, 457-476.

Cuellar, I., Harris, L. C., \& Jasso, R. (1980). An acculturation scale for Mexican American normal and clinical populations. Hispanic Journal of Behavior Sciences, 2, 199-217. 
Clark, K. E., \& Ladd, G. W. (2000). Connectedness and autonomy support in parentchild relationships: Links to children's socioemotional orientation and peer relationships. Developmental Psychology, 36, 485-498.

Denner, J., Kirby, D., Coyle, K., \& Brindis, C. (2001). The protective role of social capital and cultural norms in Latino communities: A study of adolescent births. Hispanic Journal of Behavioral Sciences, 23, 3-21.

Driscoll, A. K., Russell, S. T., \& Crockett, L. J. (2008). Parenting styles and youth wellbeing across immigrant generations. Journal of Family Issues, 29, 185-209.

Dumka, L., Roosa, M., \& Jackson, K. (1997). Risk, conflict, mothers' parenting, and children's adjustment in low-income, Mexican immigrant, and Mexican American families. Journal of Marriage and the Family, 59, 309-323.

Durrett, M. E., O’Bryant, S., \& Pennebaker, J. W. (1975). Child-rearing reports of White, Black, and Mexican-American families. Developmental Psychology, 11, 871.

Fuligni, A. J., Tseng, V., \& Lam, M. (1999). Attitudes toward family obligations among American adolescents with Asian, Latin American, and European backgrounds. Child Development, 70, 1030-1044.

Ginsburg, G. S., Siqueland, L., Masia-Warner, C., \& Hedtke, K. A. (2004). Anxiety disorders in children: Family matters. Cognitive and Behavioral Practice, 11, 28 43.

Gonzales, N. A., Barr, A., \& Formoso, D. (1997, June). Acculturation and family process among Mexican American families. Keynote address presented at the 1997 NIMH Family Research Consortium Meeting, San Antonio, Texas.

Jaccard, J., \& Turrisi, R. (2003). Interaction effects in multiple regression (2nd ed.). Thousand Oaks, CA: Sage.

Jaccard, J., Turrisi, R., and Wan, C. (1990) Interaction effects in multiple regression. Newbury Park: Sage.

Jaccard, J., \& Wan, C. (1996). LISREL analyses of interaction effects in multiple regression. Newbury Park, CA: Sage.

Julian, T., McKenry, P., McKelvey, M. (1994). Cultural variations in parenting: Perceptions of Caucasian, African-American, Hispanic, and Asian-American parents. Family Relations, 43, 30-37.

Kendall, P. C. (1994). Treating anxiety disorders in children: Results of a randomized clinical trial. Journal of Consulting and Clinical Psychology, 62, 200-210. 
Knight, G. P., Virdin, L. M., \& Roosa, M. (1994). Socialization and family correlates of mental health outcomes among Hispanic and Anglo American children: Considerations of cross-ethnic scalar equivalence. Child Development, 65, 212-224.

MacKinnon, D. P., Lockwood, C. M., Hoffman, J. M., West, S. G., \& Sheets, V. (2002). A comparison of methods to test mediation and other intervening variable effects. Psychological Methods, 7, 83-104.

McLeod, B. D., Wood, J. J., \& Weisz, J. R. (2007). Examining the association between parenting and childhood anxiety: A meta-analysis. Clinical Psychology Review, $27,155-172$.

Maccoby, E. E. (1992). The role of parents in the socialization of children: A historical review. Developmental Psychology, 28, 1006-1017.

Muthén, L. K., \& Muthén, B. O. (2007). Mplus User's Guide (Sixth Edition). Los Angeles, CA: Muthén \& Muthén.

Novy, D. M., Stanley, M. A., Averill, P., \& Daza, P. (2001). Psychometric comparability of English- and Spanish-language measures of anxiety and related affective symptoms. Psychological Assessment, 13, 347-355.

Okagaki, L., \& Sternberg, R. J. (1993). Putting the distance into students' hands: Practical intelligence for school. In R. R. Cocking \& K. A. Renninger (Eds.), The development and meaning of psychological distance (pp. 237-254). Hillsdale, NJ: Erlbaum.

Pela, O. A., \& Reynolds, C. R. (1982). Cross-cultural application of the revised-children's manifest anxiety scale: Normative and reliability data for Nigerian primary school children. Psychological Reports, 51, 1135-1138.

Rapee, R. M. (1997). Potential role of childrearing practices in the development of anxiety and depression. Clinical Psychology Review, 17, 47-67.

Rapee, R. M. (2001). The development of generalized anxiety. In M. W. Vasey \& M. R. Dadds (Eds.), The development psychopathology of anxiety (pp. 481-503). Oxford: Oxford University Press.

Reynolds, C. R., \& Richmond, B. O. (1978). What I think and feel: A revised measure of children's manifest anxiety. Journal of Abnormal Child Psychology, 6, 271-280.

Rogler, L. H., Cortes, D. E., \& Malgady, R. G. (1991). Acculturation and mental health status among Hispanics: Convergence and new directions for research. American Psychologist, 46, 585-597. 
Rollins, B. C, \& Thomas, D. L. (1979). Parental support, power, and control techniques in the socialization of children. In W. R. Burr, R. Hill, F. I . Nye, \& I. L. Reiss (Eds.), Contemporary theories about the family: Vol. 1. Research based theories (pp. 317-364). New York: Free Press.

Roosa, M. W., Morgan-Lopez, A., Cree, W., \& Spector, M. (2002). Ethnic culture, poverty, and context: Sources of influence on Latino families and children. In J. Contreras, A. Neal-Barnett, \& K. Kerns (Eds.), Latino children and families in the United States: Current research and future directions (pp. 27-44). Westport, CT: Praeger.

Satorra, A. (2000). Scaled and adjusted restricted tests in multi-sample analysis of moment structures. In R.D.H. Heijmans, D.S.G. Pollock, \& A. Satorra (Eds.), Innovations in multivariate statistical analysis. A Festschrift for Heinz Neudecker (pp. 233-247). London: Kluwer Academic Publishers.

Schaefer, E. S. (1965). Children's reports of parental behavior: An inventory. Child Development, 36, 413-424.

Schludermann, E., \& Schludermann, S. (1970). Replicability of factors in children's report of parent behavior (CRPBI). Journal of Psychology, 76, 239-249.

Schwarz, J. C., Barton-Henry, M., \& Pruzinsky, T. (1985). Assessing child rearing behaviors: A comparison of ratings made by mother, father, child, and siblings on the CRPBI. Child Development, 56, 462-479.

Silverman, W. K., Kurtines, W. M., Ginsburg, G. S., Weems, C. F., Lumpkin, P. W., \& Hicks-Carmichael, D. (1999). Treating anxiety disorders in children with group cognitive behavior therapy: A randomized clinical trial. Journal of Consulting and Clinical Psychology, 67, 995-1003.

Siqueland, L., Kendall, P. C., \& Steinberg, L. (1996). Anxiety in children: Perceived family environments and observed family interactions. Journal of Clinical Child Psychology, 25, 225-237.

Steinberg, L. (1990). Autonomy, conflict, and harmony in the family relationship. In S. S. Feldman \& G. R. Elliot (Eds.), At the threshold: The developing adolescent (pp. 255-276). Cambridge, MA: Harvard University Press.

Stephenson, M. (2000). Development and validation of the Stephenson Multigroup Acculturation Scale (SMAS). Psychological Assessment, 12, 77-88.

Szapocznik, J., \& Kurtines, W. M. (1993). Family psychology and cultural diversity: Opportunities for theory, research, and application. American Psychologist, 48, 400-407. 
U. S. Census Bureau. (2010). Overview of Race and Hispanic Origin: 2010. Retrieved April 3, 2011, from

http://www.census.gov/newsroom/releases/archives/population/cb06-72.html

U. S. Census Bureau. (2006). Nation's Population One-Third Minority. Retrieved January 8, 2011, from http://www.census.gov/newsroom/releases/archives/population/cb06-72.html

Vasey, M. W., \& Dadds, M. R. (2001). An introduction to the developmental psychopathology of anxiety. In M. W. Vasey \& M. R. Dadds (Eds.), The developmental psychopathology of anxiety (pp. 3-26). Oxford: Oxford University Press.

Weems, C. F., \& Silverman, W. K. (2006). An integrative model of control: Implications for understanding emotion regulation and dysregulation in childhood anxiety. Journal of Affective Disorders, 91, 113-124.

Wood, J. J. (2006). Parental intrusiveness and children's separation anxiety in a clinical sample. Child Psychiatry \& Human Development, 37, 73-87.

Wood, J. J., McLeod, B. D., Sigman, M., Hwang, W. C., \& Chu, B. C. (2003). Parenting and childhood depression: Theory, empirical findings, and future directions. Journal of Child Psychology and Psychiatry, 44, 134-151.

Wothke, W. (2000). Longitudinal and multi-group modeling with missing data. In T. D. Little, K. U. Schnabel, \& J. Baumert (Eds.) Modeling longitudinal and multiple group data: Practical issues, applied approaches and specific examples. Mahwah, NJ: Erlbaum.

Zayas, L. H. (1987). Toward an understanding of suicide risks in young Hispanic females. Journal of Adolescent Research, 2, 1-11. 
APPENDICES 
Table 1

Demographic Characteristics of the Sample

\begin{tabular}{|c|c|c|c|c|}
\hline Variable & Mean $(S D)$ & & $n$ & $\%$ \\
\hline \multicolumn{5}{|l|}{ Gender } \\
\hline & & Males & 291 & 54.4 \\
\hline & & Females & 244 & 45.6 \\
\hline \multicolumn{5}{|l|}{ SES } \\
\hline & & $\$ \quad 0$ to 20,999 & 102 & 19.1 \\
\hline & & $\$ 21,000$ to 40,999 & 131 & 24.5 \\
\hline & & $\$ 41,000$ to 60,999 & 83 & 15.5 \\
\hline & & $\$ 61,000$ to 80,999 & 66 & 12.3 \\
\hline & & $\$ 81,000$ to 99,999 & 41 & 7.7 \\
\hline & & Over $\$ 100,000$ & 63 & 11.8 \\
\hline & & Not reported & 49 & 9.1 \\
\hline Age & \multicolumn{4}{|l|}{$9.79(2.50)$} \\
\hline
\end{tabular}

Note. SES refers to socioeconomic status. 
Table 2

Frequency and Percentages of Primary Diagnoses

\begin{tabular}{|c|c|c|}
\hline $\begin{array}{l}\text { Primary Diagnoses } \\
(n=189)\end{array}$ & $n$ & $\%$ \\
\hline Separation Anxiety & 155 & 29.0 \\
\hline Social Phobia & 113 & 21.1 \\
\hline Specific Phobia & 54 & 10.1 \\
\hline Panic Disorder with Agoraphobia & 12 & 2.2 \\
\hline Agoraphobia without Panic & 3 & 0.6 \\
\hline Generalized Anxiety Disorder & 92 & 17.2 \\
\hline Obsessive Compulsive Disorder & 6 & 1.1 \\
\hline Posttraumatic Stress Disorder & 2 & 0.4 \\
\hline Oppositional Defiant Disorder ${ }^{a}$ & 9 & 1.7 \\
\hline Dysthmia $^{\mathrm{a}}$ & 3 & 0.6 \\
\hline ADHD - inattentive type ${ }^{a}$ & 10 & 1.9 \\
\hline ADHD - combined type ${ }^{a}$ & 10 & 1.9 \\
\hline Major Depression ${ }^{\mathrm{a}}$ & 10 & 1.9 \\
\hline Selective Mutism & 15 & 2.8 \\
\hline No Diagnosis & 21 & 3.9 \\
\hline Not reported & 20 & 3.6 \\
\hline
\end{tabular}

Note. ADHD refers to Attention Deficit Hyperactivity Disorder. All diagnoses were derived using the ADIS C/P.

a. Diagnoses listed not classified as anxiety disorders by the DSM-IV. All youth whose primary diagnosis is not classified as an anxiety disorder also met criteria for an anxiety disorder diagnosis. 
Figure 1. Conceptual Moderated Mediation Model

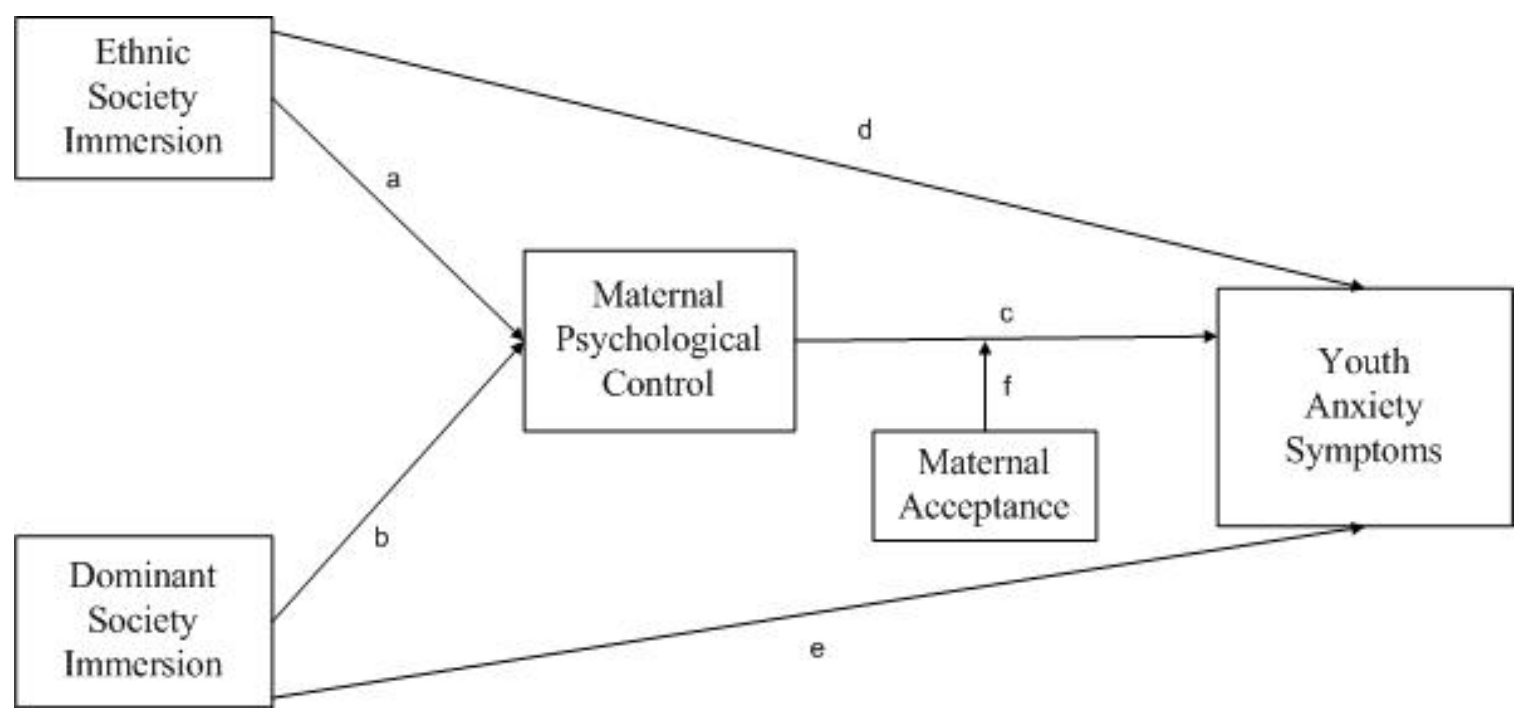


Figure 2. Youth Moderated Mediation Model

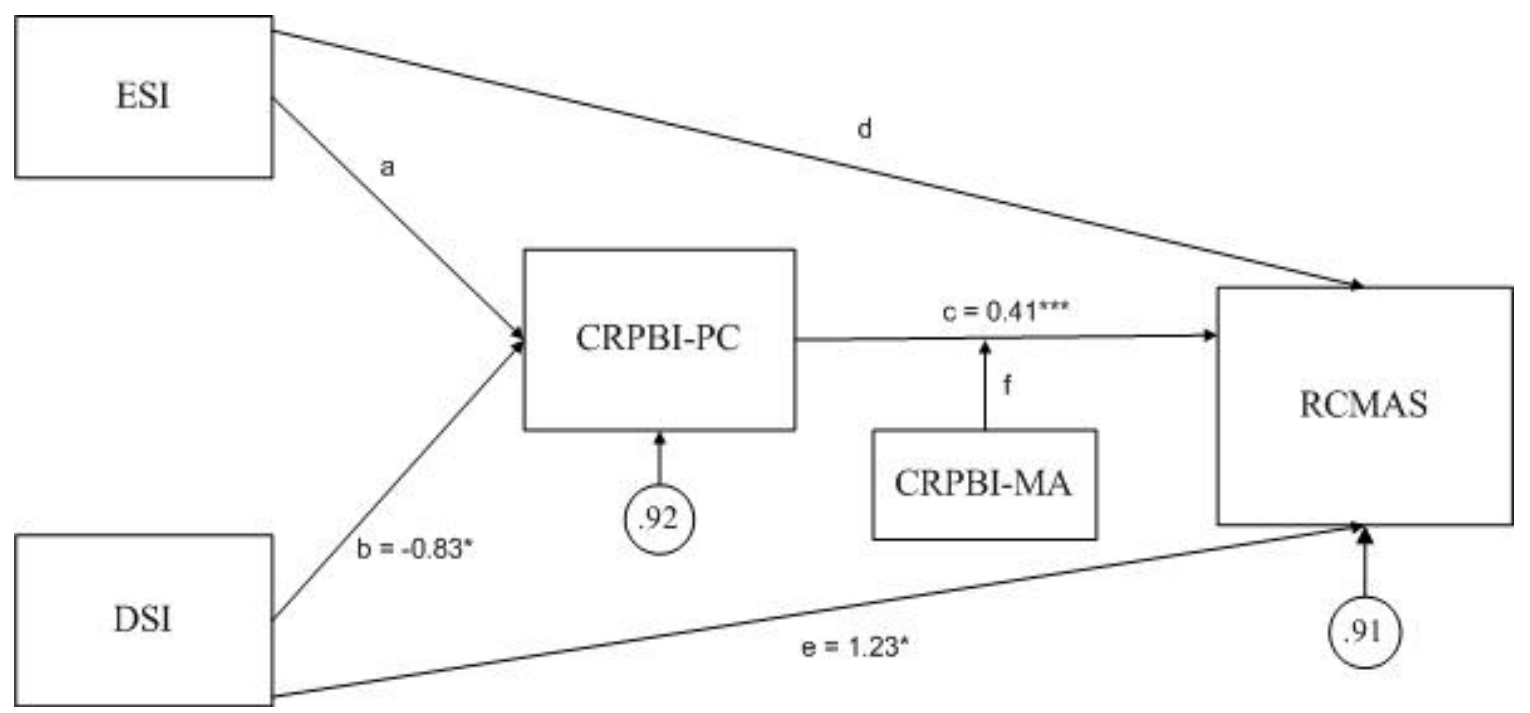

Note . ESI $=$ Ethnic Society Immersion; DSI = Dominant Society Immersion; CRPBI-PC $=$ Children's Report of the Parenting Behavior Inventory-Psychological Control; CRPBI$\mathrm{MA}=$ Children's Report of the Parenting Behavior Inventory-Maternal Acceptance; RCMAS = Revised Children's Manifest Anxiety Scale. Youth age was used as a covariate for RCMAS scores. 
Figure 3. Youth Mediation Model

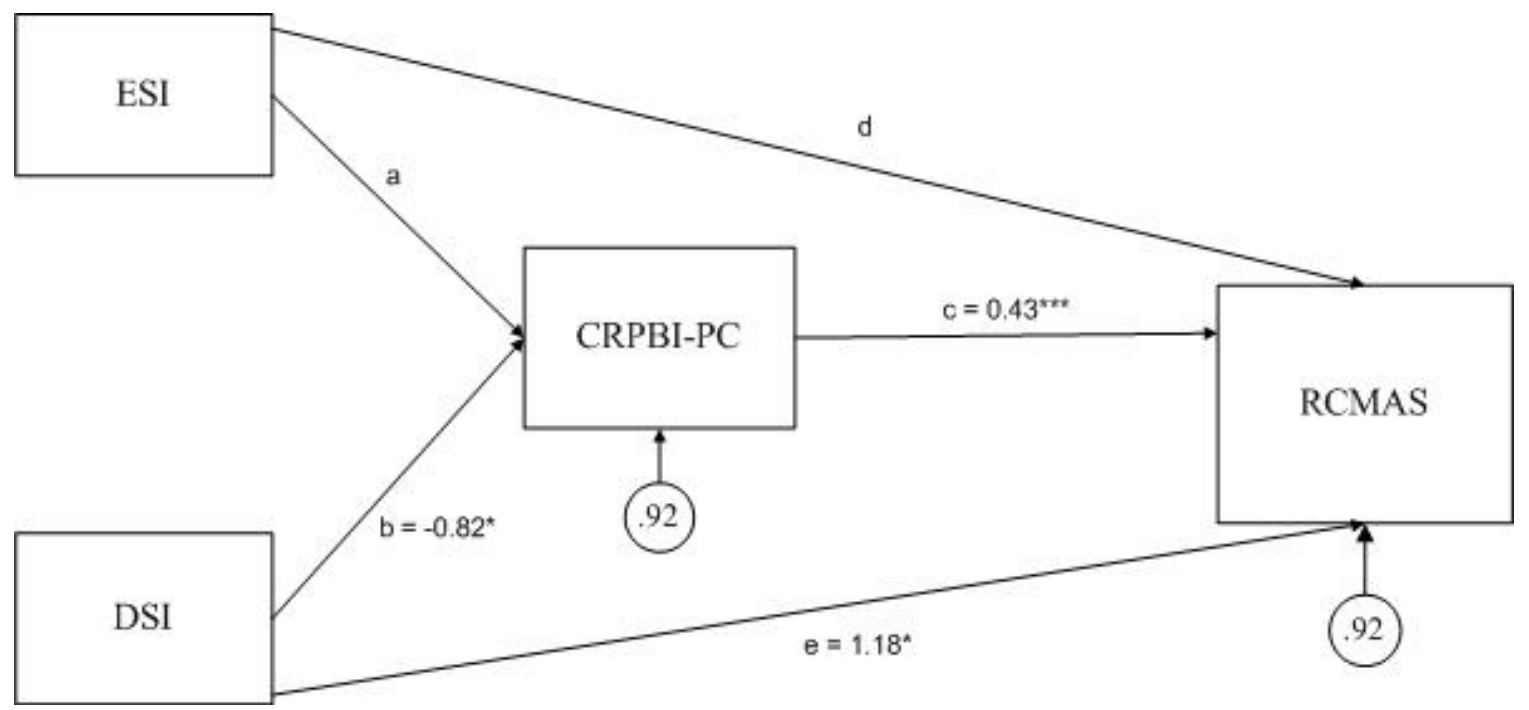

Note . ESI $=$ Ethnic Society Immersion; DSI = Dominant Society Immersion; CRPBI-PC $=$ Children's Report of the Parenting Behavior Inventory-Psychological Control; RCMAS $=$ Revised Children's Manifest Anxiety Scale. Youth age was used as a covariate for RCMAS scores. 
Figure 4. Parent Moderated Mediation Model

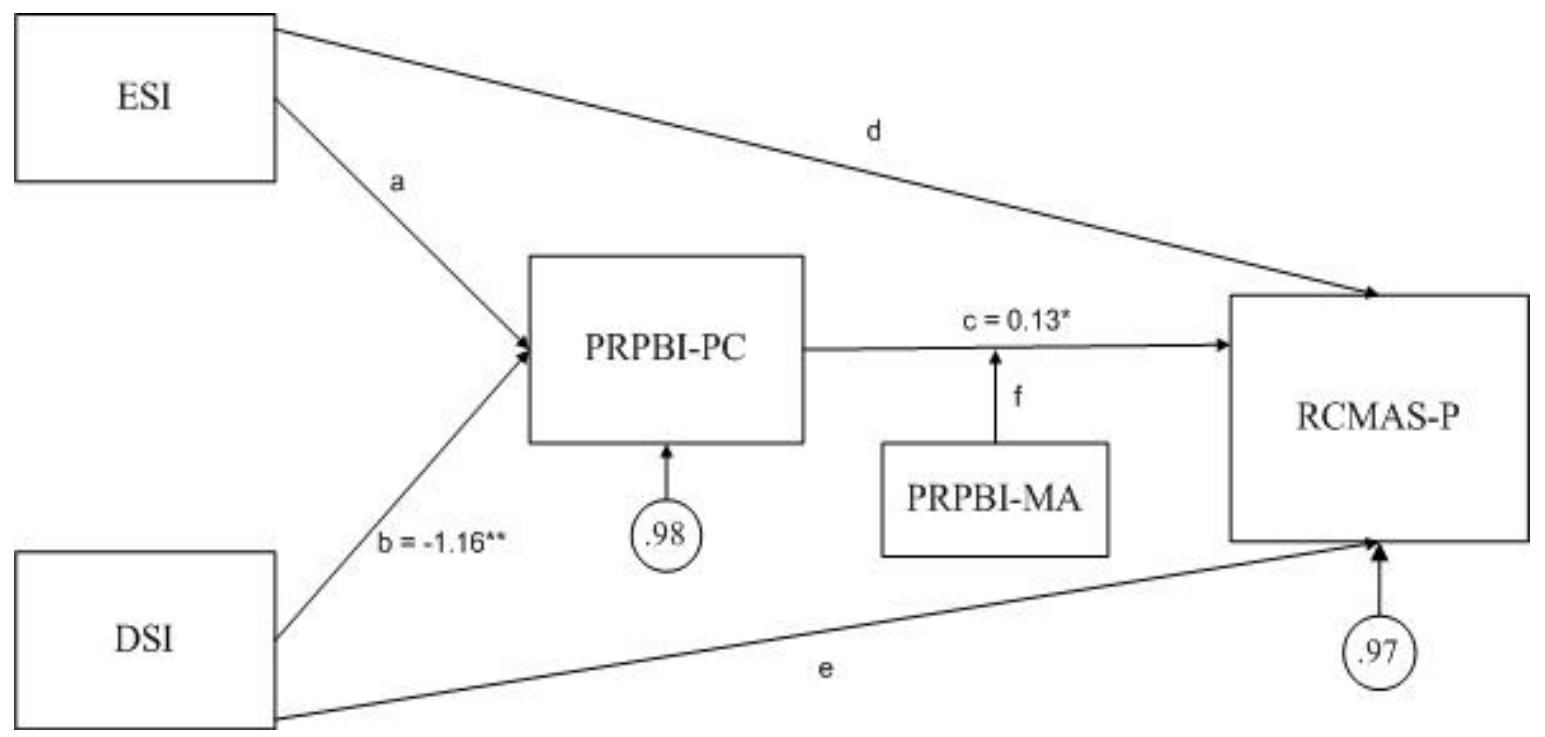

Note . ESI $=$ Ethnic Society Immersion; DSI = Dominant Society Immersion; PRPBI-PC $=$ Parenting Behavior Inventory-Psychological Control; PRPBI-MA = Parenting Behavior Inventory-Maternal Acceptance; RCMAS-P = Revised Children's Manifest Anxiety Scale-Parent Version. Youth age was used as a covariate for RCMAS-P scores. 
Figure 5. Parent Mediation Model

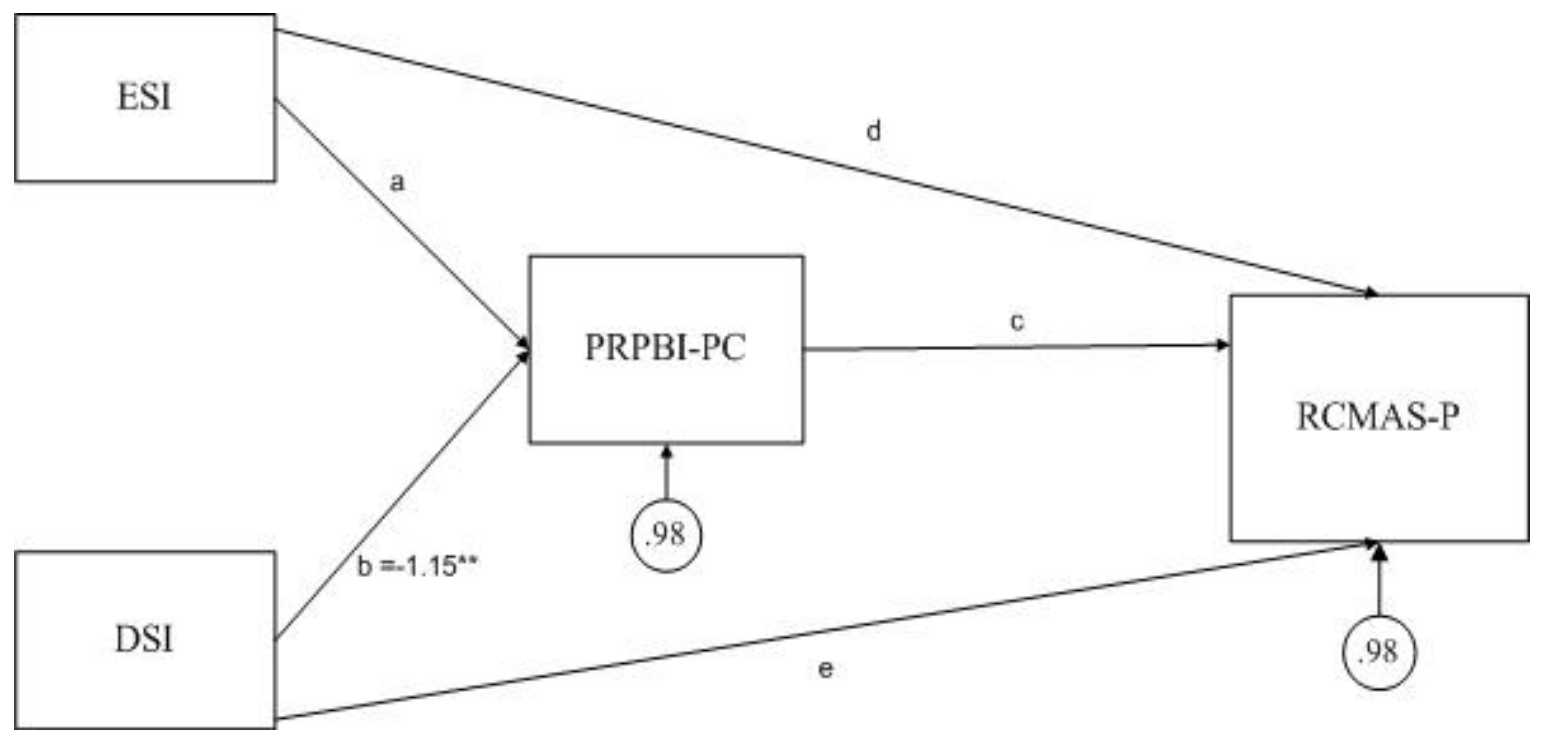

Note . ESI $=$ Ethnic Society Immersion; DSI = Dominant Society Immersion; PRPBI-PC $=$ Parenting Behavior Inventory-Psychological Control; RCMAS-P = Revised Children's Manifest Anxiety Scale-Parent Version. Youth age was used as a covariate for RCMASP scores. 